\title{
MEU CORPO, MINHA VIDA: CIDADANIA, DIREITOS HUMANOS E MULHERES
}

\author{
MY BODY, MY LIFE: CITIZENSHIP, HUMAN RIGHTS AND WOMEN
}

\author{
MI CUERPO, MI VIDA: CIUDADANÍA, DERECHOS HUMANOS Y MUJERES
}

\author{
Ana Maria Colling ${ }^{1}$, Paula Tatiane de Azevedo ${ }^{2}$
}

\begin{abstract}
RESUMO
Historicamente as mulheres avançaram em todas as áreas pelas quais lutaram - trabalho, educação, voto, métodos contraceptivos, etc., mas nesta espiral ascendente de conquistas, duas questões teimam em permanecer - o patriarcado (poder de uns sobre outras) e a violência contra as mulheres. O Brasil não carece de leis igualitárias; figuramos entre os países que mais protegem legalmente as mulheres. Mas entre a pena da lei e a cultura que sempre encarou com naturalidade o assédio, o estupro, a violência e a morte, há um longo caminho a percorrer. Neste texto onde historiamos os Direitos Humanos e a Cidadania e sua relação com as mulheres nos deparamos com um foco de poder - o corpo feminino. Historicamente desqualificado, um corpo a ser utilizado, agredido, violado. Como falar em Direitos Humanos como direitos universais, em Cidadania para todos, se nos deparamos cotidianamente com a calamidade pública que é a violência contra a mulher? Paradoxalmente como falar em direitos humanos e ética, se este mesmo corpo agredido, assassinado é aquele que produz seres humanos?
\end{abstract}

PALAVRAS-CHAVE: Direitos Humanos. Cidadania. Mulheres. Corpo.

\begin{abstract}
Historically, women have advanced in all areas they have struggled for-work, education, voting, contraceptive methods, etc. But in this ascending spiral of conquest, two issues persist in remaining patriarchy (power over one another) and violence against the women. Brazil does not lack egalitarian laws; we are among the countries that most legally protect women. But between the penalty of the law and the culture that has always naturally faced harassment, rape, violence and death, there is a long way to go. In this text where we we historicized Human Rights and Citizenship and its relationship with women, we are faced with a power focus - the female body. Historically disqualified, a body to be used, assaulted, violated. How to speak in Human Rights as universal rights, in Citizenship for all, if we are faced daily with the public calamity that is violence against women? Paradoxically how to speak in human rights and ethics, if this same beaten, murdered body is one that produces human beings?
\end{abstract}

KEYWORDS: human rights. Citizenship. Women. Body.

\section{RESUMEN}

Las mujeres avanzaron en todas las áreas por las que lucharon -trabajo, educación, voto, métodos anticonceptivos, etc., pero en esta espiral ascendente de conquistas, dos cuestiones afincanse en permanecer - el patriarcado (poder de unos sobre otras) y la violencia contra las mujeres. Brasil no carece de leyes igualitarias; figura entre los países que más protegen legalmente a las mujeres. Pero entre la pena de la ley y la cultura que siempre encaró con naturalidad el acoso, la violación, la violencia y la muerte, hay un largo camino por recorrer. En este texto donde historiamos los Derechos Humanos y la Ciudadanía

\footnotetext{
1 acolling21@yahoo.com.br

2 acolling21@yahoo.com.br
}

\begin{tabular}{l|l|l}
\hline Rev. Ciências Humanas & Frederico Westphalen, RS & Jan./abr. 2019 \\
\hline
\end{tabular}

\begin{tabular}{l|l|l} 
Recebido em: 08/04/2019 & Aceito em: 29/04/2019 & Pg. 74 - 88
\end{tabular}




\section{(1) URI|}

y su relación con las mujeres nos encontramos con un foco de poder - el cuerpo femenino. Históricamente descalificado, un cuerpo a ser utilizado, agredido, violado. ¿Cómo hablar en Derechos Humanos como derechos universales, en Ciudadanía para todos, si nos encontramos cotidianamente con la calamidad pública que es la violencia contra la mujer? Paradójicamente como hablar de derechos humanos y ética, si este mismo cuerpo agredido, asesinado es aquel que produce seres humanos?

PALABRAS CLAVE: Derechos humanos. Ciudadanía. Mujeres. Cuerpo.

\section{CONSIDERAÇÕES INICIAIS}

Iguais na lei, desiguais em todas as práticas sociais. Menores salários para trabalhos iguais, poucas chefias, várias jornadas de trabalho, mas em especial, a desigualdade, a hierarquização entre os sexos, a desqualificação do corpo feminino é radicalmente exposta na violência contra as mulheres.

Se as mulheres avançaram em suas lutas e reivindicações, o que é inegável, pois as carreiras, a educação, o voto, foram conquistas históricas árduas. Mas, neste processo, nessa espiral, onde deveriam acontecer somente avanços, duas questões teimam em permanecer em toda a história brasileira - o patriarcado e a violência contra as mulheres. Ambas questões perpassam o corpo feminino.

O corpo feminino foi e continua sendo alvo de poder. Historicamente foi desqualificado. Desde o discurso médico-filosófico dos antigos gregos, passando pela narrativa judaico-cristã, pelo discurso médico-psiquiátrico até chegar ao discurso psicanalítico, o corpo feminino sempre foi alvo de suspeitas e surpresas. O que quer dizer este corpo, enigmático, que os homens, portadores da racionalidade e donos do pensamento ocidental não conseguiam explicar?

A historiadora francesa, Michele Perrot, afirma que se o corpo está presente em toda relação de poder, o corpo das mulheres é o centro. Sua aparência, suas formas, seus gestos, suas vestimentas etc., tudo que envolve este corpo é objeto de suspeita. Suspeita, segundo ela, que visa o sexo, vulcão da terra: "Toda mulher em liberdade é um perigo e, ao mesmo tempo, está em perigo, um legitimando o outro. Se algo de mau lhe acontece, ela está recebendo apenas aquilo que merece, porque o corpo das mulheres não lhe pertence". Segundo este mesma autora,

A dimensão maior da história das relações entre os sexos, a dominação dos

\begin{tabular}{l|l|l}
\hline Rev. Ciências Humanas & Frederico Westphalen, RS & Jan./abr. 2019 \\
\hline
\end{tabular}

\begin{tabular}{l|l|l} 
Recebido em: 08/04/2019 & Aceito em: 29/04/2019 & Pg. 74 - 88
\end{tabular}




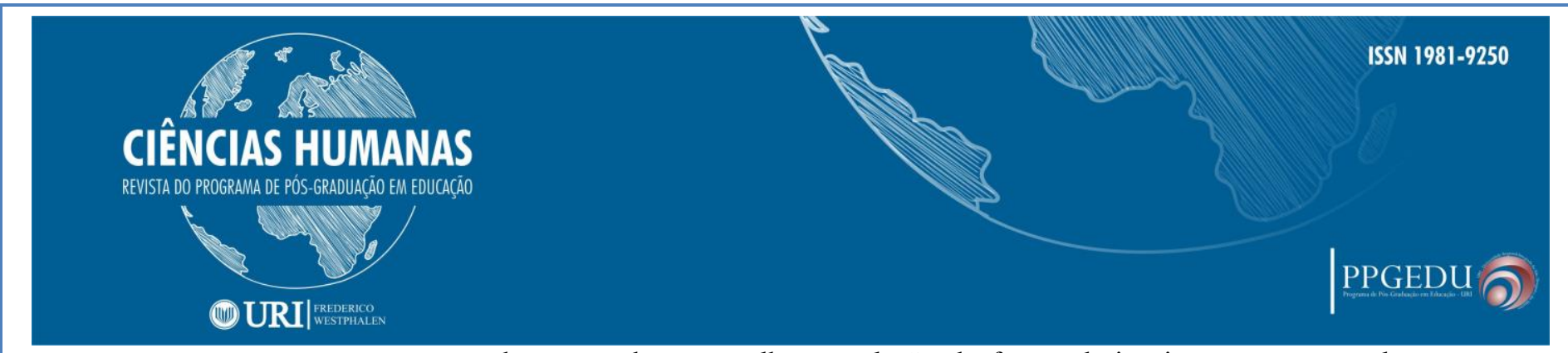

homens sobre as mulheres, relação de forças desiguais, expressa-se pela violência. Os processos de civilização a faz recuar sem aboli-la, tornando-a mais surtir e mais simbólica. Subsistem, entretanto, grandes explosões de uma violência direta e sem dissimulação, sempre pronta a ressurgir, com a tranquila segurança do direito de poder dispor livremente do corpo do Outro, este corpo que lhe pertence. (PERROT, 2005, p.454).

Este texto tem por objetivo abordar a questão dos direitos humanos e da cidadania, e sua relação com as mulheres e de que forma essas questões se relacionam com o corpo feminino, ou ainda as relações de poder construídas a partir do/no corpo feminino. Pretendemos abordar os conceitos de direitos humanos e cidadania, não como sinônimos, mas inter-relacionados. Entendemos que para exercer a cidadania, homens e mulheres devem usufruir dos direitos humanos de forma igualitária.

Os direitos humanos estão garantidos em nossa constituição cidadã de 1988. Seu primeiro artigo fala da cidadania, da dignidade da pessoa humana e dos valores sociais do trabalho. $\mathrm{O}$ artigo $5^{\circ}$ trata do direito à vida, à privacidade, a igualdade e a liberdade. Sempre entendemos os direitos humanos como fundamentais para uma sociedade, mas para os governantes do Brasil de hoje direitos humanos é discurso de comunista ou direitos de bandidos.

A desigualdade de gênero e a sua radicalização que é a violência contra as mulheres é uma afronta à equidade proposta pelos Direitos Humanos desde a sua fundação no século XVIII. A reivindicação de Direitos Humanos aplicados às mulheres ocorre porque até há pouco tempo não eram consideradas humanas, mas sim, filhas ou esposas de humanos.

Os direitos humanos (sempre no masculino) assim como a invisibilidade do feminino e a violência contra as mulheres possuem uma história. Historicizar é desconstruir o discurso para localizar o ponto de início e depois reconstruir em bases igualitárias. É somente vendo que nem sempre foi assim, que isto não faz parte da ordem natural das coisas, para mudar. Se nem sempre foi assim, se é uma construção histórica, entremeada de relações de poder/saber, podemos fazer e pensar diferente do que pensamos. Devemos lutar para que os direitos humanos sejam aplicados a todos os humanos, para viver em um mundo diferente, onde a liberdade possa ser desfrutada por todos os humanas e humanos.

\begin{tabular}{l|l|l} 
Recebido em: 08/04/2019 & Aceito em: 29/04/2019 & Pg. 74 - 88
\end{tabular}




\section{Mulheres, Direitos Humanos e Cidadania}

Os Direitos Humanos tem sua história e, é uma história masculina por excelência têm sua fundação em três documentos fundamentais tidos como textos fundadores: A Declaração da Independência dos EUA de 1776; a Declaração dos Direitos do Homem e do Cidadão de 1789 e a Declaração Universal dos Direitos Humanos decretada pela ONU em 1948. O primeiro documento é elaborado por Thomas Jefferson nos Estados Unidos após a independência da Inglaterra; o segundo, com muitas afinidades ao documento norte-americano, é consequência da Revolução Francesa e o terceiro um efeito da Segunda Guerra Mundial. Se a declaração francesa é semelhante á norteamericana, também o documento da ONU apresenta similaridades aos seus antecessores.. Se os dois primeiros falam em Direitos do Homem o terceiro avança e fala em Direitos do ser humano Mas os três silenciam sobre as mulheres.

Embaladas pelo Iluminismo e a Ilustração, a Revolução Francesa (1789) e a Revolução Americana (1776) fundam os novos direitos civis. O que distingue as declarações do século XVIII é a sua abrangência. A ruptura histórica e política efetuada pela Revolução Francesa tenta ir além da proposta norte-americana com pretensões de universalidade. Ao lançar a Declaração dos Direitos do Homem e do Cidadão, a nova burguesia no poder tenta contemplar a humanidade como um todo, determinando que este novo conceito, o de igualdade, seria para todos: declaração dos direitos civis de todos homens, de todos os países, de todos os povos, de todas etnias.

Assim como o séc. XVIII produziu o novo sujeito de direitos, produziu também a ideia de felicidade como um projeto social. Com a revolução industrial o homem descobriu que a educação, a produção de alimentos, a fabricação de coisas que necessitava como tecidos, máquinas, etc., poderia ser uma possibilidade para todos. A produção de instrumentos para se viver melhor, acenava que a felicidade poderia ser universal. Esta ideia de felicidade para todos provocou a ideia da igualdade entre todos. Liberdade, Igualdade, Fraternidade, conceitos que se transformaram em paradigmáticos após a Revolução Francesa, sintetizaram os direitos do novo cidadão e são as palavras de ordem contra as opressões passadas. 


\section{(1) URI|}

A Declaração dos direitos do homem e do cidadão é universalmente reconhecida como o momento fundador dos modernos direitos à liberdade e à igualdade. Michel Foucault identifica na tríade revolucionária, tão cara aos franceses, a delimitação de espaços e comportamentos a serem seguidos por todos os indivíduos, como dispositivos de submissão: por trás da liberdade, grande reclusão; por trás da igualdade, a escravidão do corpo; por trás da fraternidade, a exclusão, escrevia ele. (FOUCAULT, 1993)

A Declaração das Nações Unidas antes de seu artigo $1^{\circ}$ (num total de 30) diz que "todos os seres humanos nascem livres e iguais em dignidade e direitos. São dotados de razão e consciência e devem agir uns para com os outros num espírito de fraternidade", seguindo os mesmos princípios das declarações de 1776 e 1789. Localizado historicamente, numa alusão ao holocausto, marca em seu preâmbulo que

\footnotetext{
"visto que o desrespeito e o desprezo pelos direitos humanos têm resultado em atos bárbaros que ofenderam a consciências da humanidade e que o advento de um mundo em que os seres humanos tenham liberdade de expressão e crença e a liberdade de viver sem medo e privações foi proclamado como a aspiração mais elementar do homem comum (HUNT, 2009, p. 229).’”
}

Lynn Hunt no seu já clássico nos lembra que se as declarações de 1776 e 1789 tem um problema de linguagem, utilizando a expressão "direitos do homem", criada por Rousseau, a declaração da ONU, avança e, em seu texto, inclui todos os sujeitos, fala em "Direitos humanos". Os direitos humanos requerem três qualidades: ser naturais (inerentes aos seres humanos), iguais (os mesmos para todo o mundo) e universais (aplicáveis em toda a parte). Segundo Lynn Hunt, acabou sendo mais fácil aceitar a qualidade natural dos direitos do que a sua igualdade ou universalidade. A igualdade e a universalidade de direitos ainda é um tema debatido no mundo inteiro. Mas segundo este autora,

nem, o caráter natural, a igualdade e a universalidade são suficientes. Os direitos humanos só se tornam significativos quando ganham conteúdo político. Não são os direitos de humanos num estado de natureza: são os direitos de humanos em sociedade. São os direitos humanos vis-à-vis uns aos outros. E são direitos que requerem uma participação ativa daqueles que os detêm (HUNT, 2009, p.19).

Uma das prerrogativas fundamentais da liberdade e da igualdade é a autonomia.

\begin{tabular}{l|l|l}
\hline Rev. Ciências Humanas & Frederico Westphalen, RS & Jan./abr. 2019 \\
\hline
\end{tabular}

\begin{tabular}{l|l|l} 
Recebido em: 08/04/2019 & Aceito em: 29/04/2019 & Pg. 74 - 88
\end{tabular}




\section{(1)URI|}

No séc XVIII, e ainda hoje, não se imagina que todas as pessoas sejam autônomas. Para isso duas qualidades estavam implicadas: a capacidade de raciocinar e a independência de decidir por conta própria. No século XVIII em especial, as crianças, os loucos, os escravos, os criados, os sem propriedade e as mulheres não tinham independência para serem autônomos. Todos os relacionados podiam um dia tornar-se autônomos, crescendo ou comprando sua liberdade. Apenas as mulheres não tinham nenhuma destas opções: eram definidas como inerentemente dependentes de seus pais e maridos pelos aparatos jurídicos. Quando abolidas muitas das diferenças entre os homens, muitas outras permaneceram, entre elas a desigualdade entre os sexos, distinguindo um mundo inferior doméstico para as mulheres frente ao mundo público, superior, próprio dos homens.

Em 1934 quando as mulheres brasileiras conquistaram o direto ao voto transformando-as em cidadãs políticas por excelência elas em coro indagavam: Como ser cidadã e poder ser devolvida após 10 dias de casamento se não for mais virgem? Como ser cidadã e obrigada a usar o nome do marido? Como ser cidadã se a casa pertencia ao marido e os hábitos pessoais eram por ele definidos? Como explicar este paradoxo: mulher maior de idade, capaz, ser excluída da vida jurídica, ser colocada entre os loucos e os menores assim que se junta ao rol das casadas? A supremacia marital, invocada pelos códigos, baseava-se na fragilidade, na inferioridade física que, paradoxalmente, só existia para as mulheres casadas.

Passadas quase duas décadas do século XXI, com uma Constituição Cidadã, um novo código civil, Lei Maria da Penha, Lei Antifeminicídio, as mulheres ainda se perguntam: como ser cidadã autônoma se a violência contra a mulher segue seu irretocável trajeto histórico? Como ser cidadã se o estupro continua instalado na cultura brasileira? Como ser cidadã se os salários são menores para trabalho igual? Como ser cidadã se uma mulher não pode vestir a roupa que quiser, suspeitar de quase todos os homens nas ruas, nos ônibus, nos metrôs? Como ser cidadã se a gestação e a maternidade ainda são utilizadas como signo de inferioridade? Como ser cidadã se o desrespeito das mulheres na política continua sendo uma prática cotidiana?

É sobre estas questões e estes problemas que enfrentam as mulheres brasileiras, 


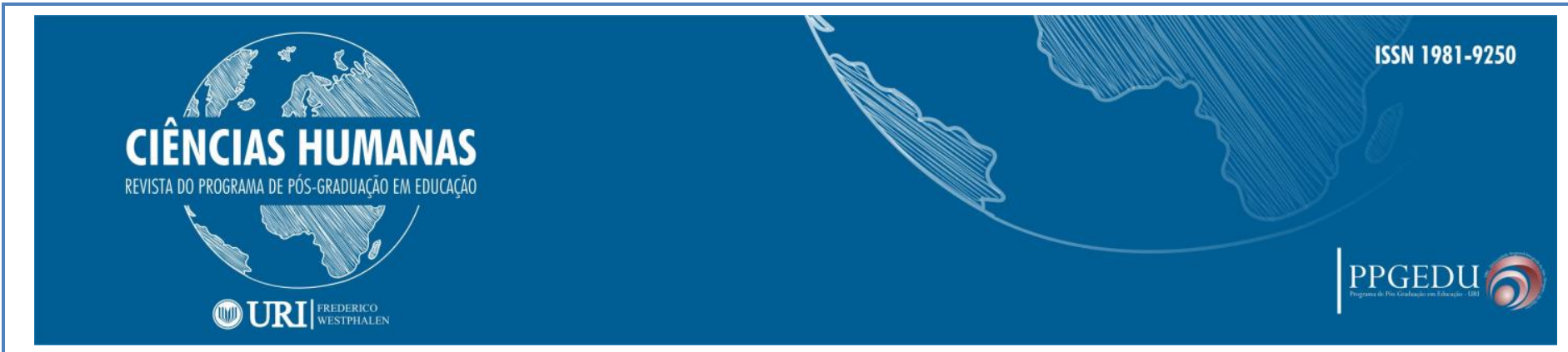

que os conceitos de direitos humanos e cidadania são colocados sob suspeita. Vimos acima que a relação das mulheres com a cidadania tem sido historicamente difícil e continua sendo uma meta a alcançar. Como afirma a espanhola Maria Xosé Agra (2015), a cidadania tem sexo-gênero e é ali onde a exclusão das mulheres está mais firmemente impressa.

Assim como voto universal que de universal só tinha o nome, pois durante décadas somente dirigido aos homens; assim como os direitos humanos no seu berço, entendia somente humanos homens e não humanas, também a cidadania tem uma direção, e não é somente masculina. Todos os sujeitos subsumidos pelo discurso moderno - mulheres, pobres, negros, índios, homossexuais estão alijados dela.

\begin{abstract}
La ciudadania moderna, la ciudadania universal, (...) confiere a los indivíduos um status formal, abstrayendo toda particularidad, marca o diferencia, sea de raza, clase, sexo o cualquier otra. Responde a la igualdad formal. Mas la igualdad formal, tras el lento y costoso acceso de las mujeres a ella, no implica que las mujeres participen plenamente de la ciudadania, o dejen de ser 'ciudadanos de segunda'. La abstracción no funciona, el individuo abstracto es masculino y las mujeres no son propiamente "indivíduos. (AGRA, 2015, p. 109/110)
\end{abstract}

O debate feminista sobre cidadania tem destacado o falso universalismo, não somente como conceito teórico, mas atravessado por um conjunto de práticas cotidianas. A cada dia nos perguntamos: cidadania para quem, cidadania onde? A face excludente da cidadania, suas fronteiras e limites nos fazem perguntar: estamos assistindo ao fim do modelo unitário de cidadania?

Las criticas feministas señalam que los modelos tradicionales de ciudadania, esto es, liberal y republicano - la ciudadania como status o como práctica coincidem em presentar al ciudadano como universal cuando em realidad es masculino. (AGRA, 2015, p. 109.)

A invisibilidade, a ausência de poder, os novos sujeitos que surgem já obscurecidos, as novas sexualidades, nos fazem pensar, para quem tem valor a cidadania? Poderemos ultrapassar o conceito que já nasceu marcado, para além da cidadania? Ainda soam atuais as palavras proferidas pelo deputado Pierre Guyomar na tribuna francesa do século XVIII: "Será preciso doravante chamá-las de mulheres ou

\begin{tabular}{l|l|l} 
Recebido em: 08/04/2019 & Aceito em: 29/04/2019 & Pg. 74 - 88
\end{tabular}




\section{CIÊNCIAS HUMANAS}

REVISTA do ProGraMa de PÓS-GRaduaç̄ó EM EduCaçāo

\section{(1)URI|}

filhas de cidadão, jamais de cidadãs. Ou cortai a palavra ou concedei a coisa”. ( GUYOMAR, 1991)

\section{Direitos Humanos, Corpo e Violência}

O corpo das mulheres tem sido palco do desrespeito aos seus direitos e sua cidadania. O corpo feminino continua no centro dos debates, muitas vezes de maneira trágica como é o caso da excisão do clitóris que mutilam meninas entre 3 e 10 anos em muitos países do mundo. Meninas levadas por suas mães para que outras mulheres quase sempre sem anestesia e assepsia, cometam o ato bárbaro. Como assim, mulheres levando mulheres para outras mulheres cometerem esta atrocidade? Como o casamento, em especial nestes países, continua a ser a única aspiração feminina, não mutiladas não serão bem aceitas socialmente e nem arrumarão quem queira casar.

No caso de países ocidentais que encaram estes atos como barbárie précivilização o corpo feminino não é privilegiado. Seu momento mais sublime que é a gravidez continua sendo signo de desigualdade, e, encarado como doença e impedimento de trabalho e educação. A violência contra as mulheres e as trans nada mais é do que o desprezo ao corpo feminino.

Mas o que é um corpo afinal? Um corpo configurado biologicamente? Efeito de relações de saber/poder moldado pela cultura? Aquilo que veste ou aquilo que despe? Um corpo que nos causa estranheza? Butler baseada em Foucault descobre que em seu argumento geral há uma constante metáfora, ou figura do corpo como uma superfície na qual a história escreve ou imprime valores culturais. (BUTLER, 2003, p. 31).

Michel Foucault nos demonstra o caráter histórico e biopolítico dos corpos. Ao analisar determinadas instituições, como escolas, fábricas, hospitais e prisões, Foucault demonstra o poder que diferentes disciplinas investem no corpo para docilizá-lo, conhecê-lo e controlá-lo. Segundo este autor, o controle da sociedade sobre os indivíduos não opera apenas pela ideologia ou pela consciência, mas tem seu começo no corpo, com o corpo. Para ele "o corpo é uma realidade biopolítica”. (FOUCAULT, 1979, p.77) 


\section{CIÊNCIAS HUMANAS}

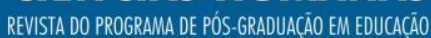

\section{(1) URI|}

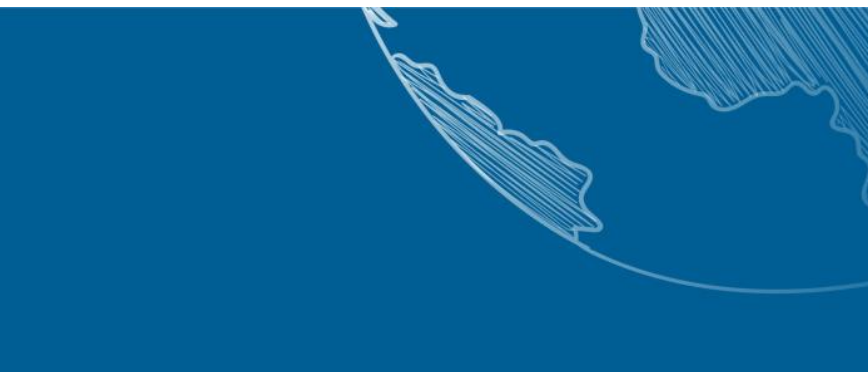

É este corpo atravessado de relações de poder/saber, um corpo que resiste e transgride como nos atuais movimentos femininos onde a palavra de ordem continua sendo "meu corpo me pertence", agora somada ao "meu útero me pertence" em defesa do aborto, ou pelo menos de sua descriminalização, que permanece no centro dos debates. Ao mesmo tempo nos incita em relacionar direitos humanos e cidadania com o desrespeito e violência que assistimos diariamente. Nenhuma mulher pode ser cidadã se o seu corpo é alvo diuturno de violência, inclusive no recesso de seu lar, que deveria ser espaço de afetos.

Como falar em Direitos Humanos, como falar em ética e cidadania quando as estatísticas de violência contra as mulheres são alarmantes. Doze mulheres são assassinadas todos os dias, em média, no Brasil. É o que mostra um levantamento dos dados oficiais dos estados relativos a 2017. São 4.473 homicídios dolosos, sendo 946 feminicídios, ou seja, casos de mulheres mortas em crimes de ódio motivados pela condição de gênero. Isso significa um aumento de 6,5\% em relação a 2016, quando foram registrados 4.201 homicídios (sendo 812 feminicídios). Segundo Samira Bueno do Fórum Brasileiro de Segurança Pública:

\footnotetext{
"Uma mulher é assassinada a cada duas horas no Brasil, taxa de 4,3 mortes para cada grupo de 100 mil pessoas do sexo feminino. Se considerarmos o último relatório da Organização Mundial da Saúde, o Brasil ocuparia a $7^{\text {a }}$ posição entre as nações mais violentas para as mulheres de um total de 83 países." ${ }^{3}$
}

As constituições estabelecem a igualdade como princípio fundamental vetando todas as distinções. Mas sabemos que a igualdade constitucional não acaba com a discriminação entre homens e mulheres que tem acompanhado a história da civilização. A desigualdade entre os sexos é historicamente construída e sua face mais cruel é a violência praticada contra a mulher, que é o atestado de desrespeito aos Direitos Humanos invocados por todas declarações.

A Declaração dos Direitos do Homem e do Cidadão de 1789 como efeito da Revolução Francesa e a decapitação de Olympe de Gouges, acusada de ser duplamente

\footnotetext{
${ }^{3}$ Dados Zero Hora - Edição 09 e 10 de março de 2019
} 


\section{(1) URI|}

traidora: traiu a natureza de seu sexo e quis ser um homem de estado, se reveste de uma importância capital para a história das mulheres. Os códigos civis implantados em praticamente todo o ocidente são heranças do misógino código napoleônico.

O Código de Napoleão de 1804 influenciou a condição da mulher, dando corpo a ideia de que a mulher é propriedade do marido, e que sua função primordial é gerar filhos. A mulher casada existe apenas na família e para a família, e é dela que tratam os códigos e é sobre ela que recaem diversos impedimentos, cristalizando sua dependência e justificando sua inferioridade. O Código napoleônico, encarnação da modernidade, editado logo após a Revolução Francesa, determinou por mais de um século a subordinação privada das mulheres e influiu decisivamente na negação à sua cidadania política.

O Código Civil brasileiro editado em 1917 assumiu as diretrizes do Código napoleônico, que legitimava o princípio da incapacidade civil das mulheres casadas, consideradas menores submetidas à autoridade do marido, desprovidas de todos os direitos políticos. O casamento, que através de vários discursos é elevado ao único ideal feminino, à única maneira de realização feminina como esposa e mãe, é, ao mesmo tempo, a gaiola da mulher; transforma-se na sujeição de um sexo pelo outro. Arranjar marido significava para a mulher perder a capacidade jurídica. O casamento privava-a de exercer os direitos pessoais e patrimoniais.

Com o casamento a mulher rebaixava-se à categoria de menor, dependente do marido, mas todas queriam casar-se, porque solteiras não eram bem vistas socialmente. Extremo paradoxo de considerar-se o estado da casada como o que oferece um maior status a uma mulher, ao mesmo tempo, como tal, sua capacidade e personalidade jurídica, já diminuída, fica consideravelmente reduzida. As mulheres eram, portanto, destinadas a viverem como menores de idade permanente.

O conceito de honra é inaugurado neste código e a honra da mulher é um dos principais motivos alegados para seu extermínio. Este conceito de honra é sexualmente localizado e o homem é o legitimador, uma vez que a honra é atribuída pela sua ausência, através da virgindade, ou pela presença no casamento. Os crimes em defesa 


\section{(1) URI|}

da honra, tanto tempo legitimados em nosso país, são perpetrados e justificados tendo como base estes códigos.

O princípio cristão "não matarás" não parece aplicar-se aos que assassinam suas esposas e companheiras. Esta decisão perpetua uma cultura de impunidades de assassinatos e agressões de esposas e amantes por parte de seus maridos e companheiros que causa perplexidade e indignação. Matava-se em nome do desprezo pela mulher e era absolvido em nome da "honra" calcado neste mesmo desprezo.

A tese jurídica da legítima Defesa da Honra deixou milhares de criminosos em liberdade, numa demonstração da conivência do estado com a violência doméstica e da persistência de uma hierarquia sexual. Alguns países chegavam a adotar a norma da impunidade total em favor do marido que "vingasse a honra" ao surpreender a mulher em adultério. No Brasil, de acordo com o Código penal de 1890, só a mulher era penalizada por adultério, sendo punida com prisão de 1 a três anos. O homem só era considerado adúltero se possuia concubina teúda e manteúda.

Cézare Lombroso, um criminologista italiano que exerceu influência nas leis jurídicas e criminológicas brasileiras, do final do século passado, apresentava a mulher como menos inteligente, menos sensível, com capacidade de se manter em castidade, condição impossível de exigir-se dos homens. Com este raciocínio justificava que as leis do adultério só atingissem a mulher, cuja natureza não a predispunha a este tipo de transgressão. Portanto, se a mulher traía era porque era má, diferentemente do homem que somente obedecia a natureza de seu sexo. Por este motivo o adultério masculino sempre disse respeito à ordem privada e o feminino transformou-se em transgressão pública. A incapacidade da mulher, estabelecida pelo Código Civil foi eliminada em 1962 com a edição do Estatuto da Mulher Casada. Mas a cultura, as mentalidades durante muito tempo conservaram o estatuto da defesa da honra masculina.

A Lei Maria da Penha, lei no 11.34 criada no Brasil em 7 de agosto de 2006, tem como principal objetivo combater a violência contra a mulher - questão de saúde pública e violadora dos direitos humanos. Segundo dados da ONU, o Brasil aparece em $53^{\circ}$ lugar no índice mundial de igualdade entre os gêneros. Na América latina aparece em $6^{\circ}$ lugar, seguindo o Uruguai, Argentina, Venezuela, Chile e Colômbia. Os dados

\begin{tabular}{l|l|l} 
Recebido em: 08/04/2019 & Aceito em: 29/04/2019 & Pg. 74 - 88
\end{tabular}




\section{(1) URI|}

levados em consideração pela ONU são a alfabetização, esperança de vida e economia. Mas, a face mais cruel da desigualdade é a violência praticada contra a mulher e encarada como natural por muitos.

Dez mulheres morrem por dia no Brasil vítimas de violência; a cada minuto uma mulher é vítima de estupro; a cada 2 minutos cinco mulheres são espancadas no Brasil. A violência contra a mulher é acirrada ou radicalizada nos países latinos. Ela é tão preocupante que a Conferência realizada em Viena em 1993, além de repudiar e condenar veementemente todas as formas de violência contra a mulher, colocou-a no mesmo estatuto de importância de outras violações brutais dos direitos humanos como o genocídio, a limpeza étnica, as torturas, a discriminação racial e o terrorismo.

Não se pode entender a violência como uma questão privada, que deve ser tratada na intimidade do lar, pois ela demanda soluções no âmbito da saúde, educação, trabalho e segurança e essas são questões públicas e comunitárias. A violência doméstica deve ser tratada como uma questão criminal. Tornar este fenômeno visível aos olhos da sociedade é um primeiro passo para que medidas sejam implementadas, e o caráter sagrado da família seja questionado.

Analisando os dados e os casos brasileiros, chegamos á conclusão que quem morre no Brasil é a ex-mulher, ex-noiva, ex-amante, ex-namorada. Se elas rompem relacionamentos, por contumazes abusos ou por qualquer outro motivo viram alvo preferencial dos violentos e violadores. Se este corpo não será mais meu não será de mais ninguém, dizem eles. Isto é tão impactante e apavorante que matam mulheres frente aos seus filhos e muitas vezes, se matam depois.

\section{CONSIDERAÇÕES FINAIS}

As práticas discursivas não são pura e simplesmente modos de fabricação de discursos. Elas tomam corpo, no conjunto das técnicas, das instituições, dos esquemas de comportamento, dos tipos de transmissão e difusão, nas formas pedagógicas que, por sua vez, as impõem e mantém. As práticas não discursivas são também parte do 


\section{CIÊNCIAS HUMANAS}

REVISTA DO PROGRAMA DE PÓS-GRADUAC̄̄o EM EDUCACĀO

\section{(1) URI|}

discurso, à medida que identificam tipos e níveis de discurso, definindo regras que ele de algum modo atualiza.

Os discursos que nomearam o masculino e o feminino se inculcaram profundamente na cultura ocidental e estabeleceram a preponderância do masculino e a subordinação do feminino. Michel Foucault encara o discurso como prática social. Em sua célebre aula A Ordem do Discurso, afirma que o discurso é produzido em razão das relações de poder. Por outro lado o discurso numa relação saber x poder produz realidade, produz verdade:

\footnotetext{
Ora, essa vontade de verdade, como os outros sistemas de exclusão, apóia-se sobre um suporte institucional: é ao mesmo tempo reforçada e reconduzida por todo um compacto conjunto de práticas como a pedagogia, é claro, como o sistema de livros, da edição, das bibliotecas, como as sociedade de sábios de outrora, os laboratórios hoje. Mas ela é reconduzida, mais profundamente sem dúvida, pelo modo como o saber é aplicado em uma sociedade, como é valorizado, distribuído, repartido e de certo modo atribuído (FOUCAULT, 1996, p. 17).
}

Combater estes discursos que transformaram-se em práticas discursivas e não discursivas é um trabalho árduo que exige a atenção de todas as instituições. família, escola, mídia, igreja e outras devem reconhecer o trabalho "eficiente" que foi efetivado durante séculos para subordinar e excluir as mulheres, e proporcionar a sua desconstrução. Abrir os discursos, mostrar como e quando foram arquitetados, desconstruí-los, é uma tarefa árdua, difícil e necessária. A radical desigualdade entre os sexos - a violência contra a mulher por ser transnacional e atravessar todas as categorias como classe, raça, etnia, geração, ter se transformado em chaga mundial e caso de saúde pública, necessita a convocação dos direitos humanos para combatê-la.

A desigualdade entre homens e mulheres é uma marca cultural que aparece em todo o ocidente. Como afirma Michelle Perrot, tão longe quanto nosso olhar histórico alcança só enxergamos a dominação masculina. Se as mulheres, e também os homens, são simplesmente um efeito de práticas discursivas e não discursivas, como nos ensina Michel Foucault, reconhecer os discursos e as práticas que nomearam as mulheres, o lugar social, as tarefas, suas atribuições, é tarefa primeira para a democratização e a igualização nas relações entre os gêneros.

\begin{tabular}{l|l|l} 
Recebido em: 08/04/2019 & Aceito em: 29/04/2019 & Pg. 74 - 88 \\
\hline
\end{tabular}




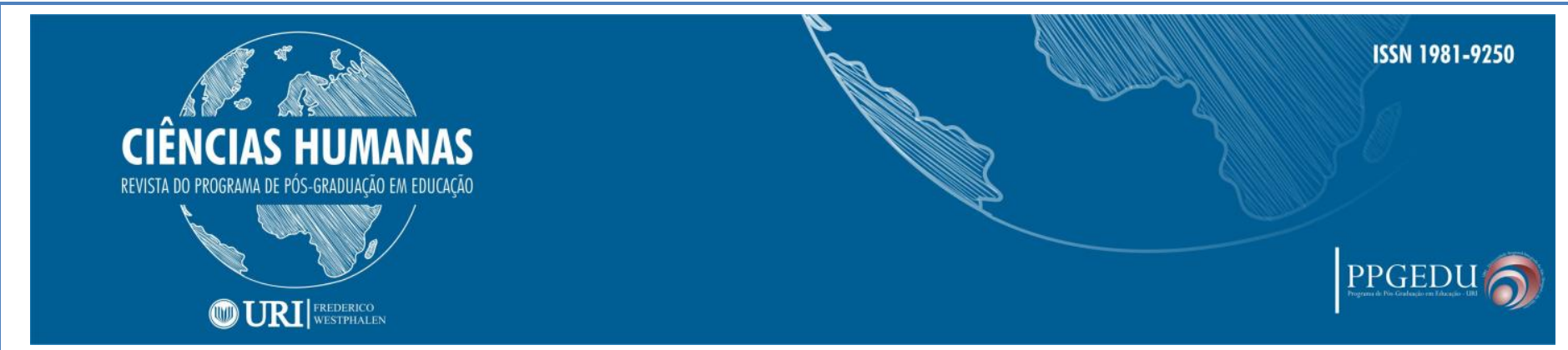

Este texto foi construído por duas historiadoras feministas. Este lugar de fala, nos permite olhar com estranheza inclusive as "singelas" piadas ditas por parentes e amigos, as frases estampadas nos para-choques de caminhões que atravessam as estradas brasileiras, também contribuem para que tantas pessoas assistam com naturalidade o desrespeito às mulheres. As políticas públicas para seu combate existem, mas a cultura, estabelecida há séculos em nossa história, esbarra as leis igualitárias.

A questão ética atravessa toda a relação entre direitos humanos, cidadania e mulheres e estabelece um paradoxo. O corpo feminino, num tempo em que a cultura do estupro e os feminicídios são alarmantes, encarado desde sempre como objeto de consumo, um corpo a ser utilizado, violado, estuprado, é o mesmo corpo que oferece ao mundo novas vidas, novos seres, homens e mulheres.

\section{REFERÊNCIAS}

GUYIOMAR. In: Palavras de Homens (1790-1793). Rio de janeiro: Nova Fronteira, 1991.

BONACCHI, Gabriela; GROPPI, Angela (orgs.). O dilema da cidadania. Direitos e deveres das mulheres. São Paulo: Unesp, 1995.

BUTLER, Judith. Problemas de Gênero. Feminismo e subversão da identidade. Rio de Janeiro: Civilização Brasileira, 2003.

COLLING, Ana Maria. Tempos diferentes, discursos iguais: a construção do corpo feminino na história. Dourados: Editora UFGD, 2014.

COLLING, Ana Maria. Direitos humanos para que humanos? In: Fundamentos para educação em Direitos Humanos. São Leopoldo: Sinodal/EST, 2011.

COLling, Ana Maria. Direitos Humanos. In: Dicionário Crítico de Gênero. Dourados: Ed. UFGD, 2015.

COLling, Ana Maria. Pós-cidadania feminina. In: Revista Territórios e Fronteiras. Cuiabá: UFMT, 2017.

\begin{tabular}{l|l|r} 
Recebido em: 08/04/2019 & Aceito em: 29/04/2019 & Pg. 74 - 88
\end{tabular}


FOUCAULT, Michel. Microfísica do poder. Rio de Janeiro: Edições Graal, 1979.

FOUCAULT, Michel. A Ordem do Discurso. São Paulo: Edições Loyola, 1996.

FOUCAULT, Michel. Verdade e Subjetividade. In: Michel Foucault. Uma analítica da Experiência. Lisboa: Edições Cosmos, 1993.

GOELLNER, Silvana Vilodre. Corpo. In: Dicionário Crítico de Gênero. Dourados: UFGD, 2015.

HUNT, Lynn. A invenção dos direitos humanos: uma história. São Paulo: Companhia das Letras., 2009.

PERROT, Michelle. As mulheres e os silêncios da História. Bauru,SP: EDUSC, 2005.

REVEL, Judith. Foucault. Conceitos essenciais. São Paulo: Claraluz, 2005.

ROMERO, Maria Xosé. Ciudadania. In: : Dicionário Crítico de Gênero. Dourados: UFGD, 2015. 